\title{
Euterpe edulis Extract but Not Oil Enhances Antioxidant Defenses and Protects against Nonalcoholic Fatty Liver Disease Induced by a High-Fat Diet in Rats
}

\author{
Rodrigo Barros Freitas, ${ }^{1}$ Rômulo Dias Novaes, ${ }^{2}$ Reggiani Vilela Gonçalves, ${ }^{3}$ \\ Bianca Gazolla Mendonça, ${ }^{1}$ Eliziária Cardoso Santos, ${ }^{4}$ Andréia Queiroz Ribeiro, ${ }^{5}$ \\ Luciana Moreira Lima, ${ }^{6}$ Luciano Gomes Fietto, ${ }^{1}$ Maria do Carmo Gouveia Peluzio, ${ }^{5}$ \\ and João Paulo Viana Leite ${ }^{1}$ \\ ${ }^{1}$ Department of Biochemistry and Molecular Biology, Federal University of Viçosa, 36570-000 Viçosa, MG, Brazil \\ ${ }^{2}$ Department of Structural Biology, Federal University of Alfenas, 37130-000 Alfenas, MG, Brazil \\ ${ }^{3}$ Department of Animal Biology, Federal University of Viçosa, 36570-000 Viçosa, MG, Brazil \\ ${ }^{4}$ School of Medicine, Federal University of Jequitinhonha and Mucuri Valleys, 39100-000 Diamantina, MG, Brazil \\ ${ }^{5}$ Department of Nutrition and Health, Federal University of Viçosa, 36570-000 Viçosa, MG, Brazil \\ ${ }^{6}$ Department of Medicine and Nursing, Federal University of Viçosa, 36570-000 Viçosa, MG, Brazil \\ Correspondence should be addressed to João Paulo Viana Leite; jpvleite@ufv.br
}

Received 13 April 2016; Revised 13 May 2016; Accepted 16 May 2016

Academic Editor: Salah A. Sheweita

Copyright (C 2016 Rodrigo Barros Freitas et al. This is an open access article distributed under the Creative Commons Attribution License, which permits unrestricted use, distribution, and reproduction in any medium, provided the original work is properly cited.

We investigated the effects of E. edulis bioproducts (lyophilized pulp [LEE], defatted lyophilized pulp [LDEE], and oil [EO]) on nonalcoholic fatty liver disease (NAFLD) induced by a high-fat diet (HFD) in rats. All products were chemically analyzed. In vivo, 42 rats were equally randomized into seven groups receiving standard diet, HFD alone or combined with EO, LEE, or LDEE. After NAFLD induction, LEE, LDEE, or EO was added to the animals' diet for 4 weeks. LEE was rich in polyunsaturated fatty acids. From LEE degreasing, LDEE presented higher levels of anthocyanins and antioxidant capacity in vitro. Dietary intake of LEE and especially LDEE, but not EO, attenuated diet-induced NAFLD, reducing inflammatory infiltrate, steatosis, and lipid peroxidation in liver tissue. Although both E. edulis bioproducts were not hepatotoxic, only LDEE presented sufficient benefits to treat NAFLD in rats, possibly by its low lipid content and high amount of phenols and anthocyanins.

\section{Introduction}

Nonalcoholic fatty liver disease (NAFLD) has increased worldwide and has been widely associated with metabolic diseases such as obesity and dyslipidemia [1,2]. Although the pathogenesis of NAFLD is complex and multifactorial, lifestyle, especially unhealthy dietary habits, is a pivotal risk factor for this condition [3-5]. NAFLD has become the most common liver disease in the United States and developed countries $[1,3,5]$. It is recognized that NAFLD develops as a consequence of immune-inflammatory mechanisms, which trigger the overproduction of reactive oxygen species (ROS) and reactive liver damage $[1,6]$. In the absence of effective treatments, some patients with NAFLD may progress to nonalcoholic steatohepatitis (NASH), cirrhosis, hepatocellular carcinoma, liver failure, and death $[2,4]$.

In the last decades, foods rich in flavonoids and anthocyanins have been marketed as nutraceuticals or functional foods [7-9], whose therapeutic potential is often claimed, but mostly unproven [10]. A broad spectrum of biological activity has been attributed to polyphenols. However, particularly their immunomodulatory (i.e., anti-inflammatory) and antioxidant properties, as well as the alleged "absence of side effects," have contributed to the wide acceptance of such 
substances in daily health care $[10,11]$. Since in vitro and in vivo evidences of the therapeutic efficiency and biosafety of dietary intake of polyphenol-based products are frequently conflicting $[10,12,13]$, to determine whether polyphenol supplementation could be useful for treating metabolic disturbances, including NAFLD, represents a challenging task.

Considering that polyphenols can modulate inflammation, oxidative stress, and energy metabolism [12-14], the rational screening of vegetable extracts rich in polyphenols has been considered a promising strategy for the development of new products potentially applicable in the management of metabolic disorders $[7,12,14]$. The fruit of the palm Euterpe edulis Mart. (Arecaceae), also called "açaí," has emerged as an important source of natural antioxidants, especially anthocyanins [13, 15-17]. Recently, our research group identified a high content of anthocyanins in an $E$. edulis extract and a remarkable antioxidant potential in vitro $[13,17]$. Furthermore, dietary intake of $E$. edulis extract alone [17] or combined with aerobic exercise training [13] was effective in attenuating genetically determined dyslipidemia and steatosis in apolipoprotein E knockout mice $\left(\mathrm{ApoE}^{-/-}\right)$ fed a normocaloric diet [17]. However, the biological potential of E. edulis pulp and its derivatives to treat environmental dyslipidemia and NAFLD (determined by dietary intake) in vivo and its applicability as a functional food still needs to be proven. Thus, in the present study, we produced three derivatives of E. edulis fruit (lyophilized pulp, defatted lyophilized pulp, and pulp oil) and investigated the effect of dietary supplementation with these derivatives on morphofunctional liver injury induced by a high-fat diet in rats. We specifically hypothesized that supplementation with E. edulis derivatives, especially the extract rich in phenols and anthocyanins, would protect liver tissue against NAFLD.

\section{Methods and Materials}

2.1. Plant Material and Extraction of LEE, LDEE, and EO. E. edulis fruit was collected in an Atlantic Forest biome (latitude: -20, 97337439; longitude: -42 , 52883943; height: $744.661 \mathrm{~m})$, Brazil. Ripe fruits were selected, weighed, and disinfected with chlorinated water. The pulp was separated in an industrial depulper, passed through a fine mesh screen, and lyophilized (Liotop lyophilizer, Brazil). The lyophilized pulp of E. edulis was named LEE. An LEE sample was subjected to oil extraction by a defatting process $(18.0 \mathrm{~g}$ of LEE was extracted with $600 \mathrm{~mL}$ ethyl ether using a Soxhlet extractor for $12 \mathrm{~h}$ ). The lipophilic solvent was completely removed by rotary evaporator, producing $E$. edulis fruit oil (EO). The remaining defatted lyophilized extract of E. edulis fruit was named LDEE.

2.2. LEE and LDEE Centesimal Composition. The extracts were analyzed for moisture, ash, lipid, protein, and carbohydrate according to the official methods described by the Association of Official Analytical Chemists (AOAC) [18]. Total lipids were quantified after extraction with ether in the Soxhlet extractor. The total protein content was measured by the classic Kjeldahl method, and carbohydrate content was determined by percentage difference by subtracting the values of moisture, ash, lipids, and proteins [18]. The levels of alimentary soluble and insoluble fiber were determined by a gravimetric-enzymatic method [19] using a commercial kit (Sigma-Aldrich, Brazil). Fibers fractionation was performed according to the Van Soest method [19]. The estimated percentage of cell wall (cellulose, hemicellulose, and lignin) is given by the sum of the neutral detergent-soluble fractions. The less digestible portion of the cell wall (cellulose and lignin) was estimated by analysis of fiber in acid detergent in the insoluble fraction.

2.3. Spectrophotometric Determination of Phenolic Compounds and Anthocyanins in LEE and LDEE. The total phenolic content was determined with the Folin-Ciocalteu method using gallic acid as the standard [20]. The absorbance at $765 \mathrm{~nm}$ was evaluated by spectrophotometry. The results were expressed in mg of gallic acid equivalent per gram of dry extract (mg GAE/g). The total anthocyanin content (TAC) was determined according to Cheng and Breen [21]. The absorbance of the mixtures was measured at 520 and $700 \mathrm{~nm}$ in buffers at $\mathrm{pH} 1.0$ and 4.5. TAC ( $100 \mathrm{~g} / \mathrm{g}$ of sample) was calculated using the equation for cyanidin-3-glucoside: TAC $(\% \mathrm{w} / \mathrm{w})=A \times \mathrm{MW} \times \mathrm{DF} \times V \times 100 \% / \varepsilon \times l W$, where $A=\left(A_{520}-A_{700}\right)_{\mathrm{pH} 1.0}-\left(A_{520}-A_{700}\right)_{\mathrm{pH} 4.5}$, MW (cyanidin3 -glucoside molecular weight $)=449.2 \mathrm{~g} / \mathrm{mol}$, DF is dilution factor (0.4), $\varepsilon$ (cyanidin-3-glucoside extinction coefficient) $=$ $26.900 \mathrm{~mol} / \mathrm{L}, l$ is optical path in $\mathrm{cm}, W$ is weight of sample (mg), and 103 is conversion factor from $\mathrm{g}$ to $\mathrm{mg}$.

\subsection{Determination of LEE and LDEE Antioxidant Activity.} The antioxidant activity of LEE and LDEE was determined in vitro by the stable organic free radical DPPH $(2,2-$ diphenyl-1-picrylhydrazyl) photocolorimetric method [22]. DPPH reagent (Sigma-Aldrich, USA) was resuspended with methanol to obtain a DPPH working solution at $0.06 \mathrm{mM}$ or $60 \mu \mathrm{M}$. Solutions were prepared from LEE and LDEE in different concentrations ( 0.1 to $25.0 \mathrm{mg} / \mathrm{mL}$ ). An aliquot of each solution $(0.1 \mathrm{~mL})$ was added to DPPH solution $(0.06 \mathrm{mM})$. The solutions were read in a spectrometer at $515 \mathrm{~nm}$ and DPPH radical scavenging activities were calculated: \% DPPH radical scavenging $=\left(\left[A_{\text {control }}-A_{\text {sample }}\right] / A_{\text {control }}\right) \times 100$.

2.5. Analysis of Tocopherols and Tocotrienols in LEE, LDEE, and EO. The extraction and analysis of vitamin E components $(\alpha-, \beta-, \gamma$-, and $\delta$-tocopherols and tocotrienols) were performed according to Cardoso et al. [23]. The vitamin E components were analyzed by HPLC using $15 \mu \mathrm{L}$ LDEE, $10 \mu \mathrm{L}$ LEE, and $5 \mu \mathrm{L}$ EO. Peak identification was based on comparison of RT values with six authentic standards of tocopherols and tocotrienols. The quantification was performed by an analytical curve constructed from injection of six increasing concentrations of standard solutions. The total content of vitamin $\mathrm{E}$ was calculated by adding the components of the vitamin E identified in the samples. 
2.6. Fatty Acids Profile in EO. The fatty acid composition of EO was determined by gas chromatography according to the protocols described by AOAC [18].

2.7. In Vivo Assay. Male Wistar rats (30 days old, weighing $85 \pm 5 \mathrm{~g}$ ) were used. The animals were maintained under controlled conditions with light/dark periods of $12 / 12 \mathrm{~h}$, temperature set to $21 \pm 2^{\circ} \mathrm{C}$, and relative air humidity of 60 $70 \%$. All experiments were approved by the Ethics Committee for Animal Research of the Federal University of Viçosa (protocol 41/2014).

2.8. Experimental Design and Diets. Forty-two animals were randomly assigned to seven groups with six animals each as follows: (1) HFD alone or combined with (2) 4\% EO; (3) and (4) $5 \%$ or $10 \%$ LEE; (5) and (6) $5 \%$ or $10 \%$ LDEE; (7) control animals receiving a standard diet. Animals in groups G1 to G6 received a high-fat diet (HFD, cafeteria diet) for 4 weeks to induce hepatic damage [6]. After this period, LEE, LDEE, or EO was added to the animals' diet for another 4 weeks. Animals in G7 (control group) were concurrently treated with a standard diet for rodents (Presence, Paulínia, SP, Brazil). The HFD consisted of ham pâté, mortadella, bacon, chocolate, powdered milk, potato chips, and a commercial diet for rats $(2: 1: 1: 1: 1: 1: 1)$ totaling $50 \%$ fat, $20 \%$ protein, and $30 \%$ carbohydrate [6]. All the diets and water were provided ad libitum. During the experiment, animals were weighed every 3 days and food intake was measured daily. After the experimental period, the animals were euthanized by cardiac puncture under anesthesia in a halothane chamber.

2.9. Histopathology and Stereology. Liver samples (median lobe) were fixed in Bouin's solution and dehydrated ethanol and embedded in paraffin. Histological sections ( $4 \mu \mathrm{m}$ thick) were cut and stained with hematoxylin and eosin (H\&E). Morphological changes in liver tissue were examined by the stereological method, using a test system of 300 points in a standard test area (At) of $73 \times 10^{3} \mu \mathrm{m}^{2}$. Sixty histological fields from each group ( $\times 400$ magnification) were randomly sampled and a total of $4.65 \times 10^{4} \mu \mathrm{m}^{2}$ liver area was analyzed. To avoid repeated analysis of the same histological area, sections were evaluated in semiseries, using one of every 20 sections. The volume densities of hepatocytes $\left(V_{\mathrm{v}}[\right.$ hep], \%), interstitium $\left(V_{\mathrm{v}}\right.$ [int], \%), sinusoid capillaries $\left(V_{\mathrm{v}}\right.$ [inf], \%), inflammatory cells $\left(V_{\mathrm{v}}\right.$ [inf cells], \%), and lipid droplets $\left(V_{\mathrm{v}}\right.$ [LD], \%) were estimated [24]. The volume densities $\left(V_{\mathrm{v}}\right)$ were estimated by counting points using the following formula: $V_{\mathrm{v}}$ $=P_{\mathrm{P}}$ [structure $] / P_{\mathrm{T}}$, where $P_{\mathrm{P}}$ is the number of points situated over the structure of interest and $P_{\mathrm{T}}$ is the total test points of the test system $[25,26]$. The volumes of 50 hepatocyte nuclei $\left(V[\mathrm{HN}], \mu \mathrm{m}^{3}\right)$ for each animal were determined according to the kariometric method previously described [27]. All morphological analyses were performed using Image ProPlus 4.5 image analysis software (Media Cybernetics, Silver Spring, MD, USA) $[26,28]$.
2.10. Oxidative Stress. Lipid peroxidation in liver tissue was evaluated by measuring thiobarbituric acid reactive substances (TBARS) [29]. Briefly, a liver sample $(100 \mathrm{mg})$ was homogenized in phosphate buffer $(\mathrm{pH} 7.0)$ and then centrifuged $(10000 \times \mathrm{g}, 10 \mathrm{~min})$ and the supernatant was reacted with thiobarbituric acid solution (trichloroacetic acid $15 \%$, thiobarbituric acid $0.375 \%$, and $0.25 \mathrm{~N} \mathrm{HCl}$ ) for $15 \mathrm{~min}$. The formation of TBARS was spectrophotometrically monitored at $535 \mathrm{~nm}$ as previously described.

Catalase (CAT) activity was evaluated in liver supernatant according to the method described by Aebi [30] by measuring the rate of $\mathrm{H}_{2} \mathrm{O}_{2}$ decomposition over $1 \mathrm{~min}$. Glutathiones-transferase (GST) activity was determined spectrophotometrically by the product formed from the complexation of reduced glutathione with 1-chloro-2,4-dinitrobenzene according to Keen et al. [31]. SOD activity was estimated by a xanthine oxidase method based on the production of hydrogen peroxide $\left(\mathrm{H}_{2} \mathrm{O}_{2}\right)$ and the reduction of nitroblue tetrazolium [32].

2.11. Biochemical Parameters. Blood samples were collected and centrifuged, and the serum was used for the biochemical determination of ultrasensitive C-reactive protein (CRP), total cholesterol, triacylglycerol, alanine aminotransferase (ALT), and aspartate aminotransferase (AST). All parameters were analyzed using commercial kits according to the manufacturer's directions (Human In Vitro Diagnostics, Minas Gerais, Brazil) [24, 26, 28].

2.12. Statistical Analysis. The data were expressed as means \pm standard deviations (mean $\pm \mathrm{SD}$ ). The normality in data distribution was verified using the D'Agostino-Pearson test. The morphological data were submitted to the Kruskal-Wallis test and the biochemical data were analyzed by unifactorial one-way analysis of variance (one-way ANOVA) followed by the Student-Newman-Keuls (SNK) post hoc test for multiple comparisons. Statistical significance was set at $p<0.05$.

\section{Results}

The levels of total fiber (soluble and insoluble) and carbohydrate were higher in LDEE (fiber, 59.58\%; carbohydrate, $77.74 \%$ ) compared to LEE (fiber, $44.81 \%$; carbohydrate, $62.66 \% ; p<0.05)$. Protein content was low and similar in LEE $(7.34 \%)$ and LDEE (8.88\%; $p>0.05)$. The lipid content of LEE (25\%) was adequately removed after the degreasing process. The resultant LDEE presented a dramatic reduction $(-2134 \mathrm{~kJ} / 100 \mathrm{~g})$ in caloric content (LEE, $3214 \mathrm{~kJ} / 100 \mathrm{~g}$, versus LDEE, $1080 \mathrm{~kJ} / 100 \mathrm{~g}$, Table 1).

The total polyphenol and anthocyanin content was higher in LDEE compared to LEE $(p<0.05)$. After LEE degreasing, LDEE was enriched with $46.53 \%$ of anthocyanins $(p<0.05)$. The antioxidant activity of LDEE $(1428 \mathrm{mg} / \mathrm{L})$ was $52.72 \%$ higher compared to LEE ( $3020 \mathrm{mg} / \mathrm{L}, p<0.05$, Table 2$)$.

The concentrations of $\alpha$-, $\beta$-, and $\gamma$-tocopherol isomers identified in EO were higher than in LEE and LDEE (EO > LEE > LDEE). Total vitamin E levels and $\alpha$ tocopherol activity were also higher in EO compared to LEE 
TABLE 1: Centesimal chemical composition of the lyophilized extracts of E. edulis fruits before and after degreasing.

\begin{tabular}{lcc}
\hline Components & LEE (\%) & LDEE (\%) \\
\hline Moisture & $2.37 \pm 0.40^{\mathrm{a}}$ & $9.29 \pm 0.80^{\mathrm{b}}$ \\
Ash & $3.04 \pm 0.10^{\mathrm{a}}$ & $4.09 \pm 0.20^{\mathrm{b}}$ \\
Protein & $7.34 \pm 0.60^{\mathrm{a}}$ & $8.88 \pm 1.10^{\mathrm{a}}$ \\
Total lipid & $24.59 \pm 1.50$ & - \\
Carbohydrates & $62.66 \pm 2.40^{\mathrm{a}}$ & $77.74 \pm 1.80^{\mathrm{b}}$ \\
$\quad$ Soluble fibers & $1.80 \pm 0.00^{\mathrm{a}}$ & $2.39 \pm 0.010^{\mathrm{b}}$ \\
$\quad$ Insoluble fibers & $43.11 \pm 0.20^{\mathrm{a}}$ & $57.19 \pm 0.30^{\mathrm{b}}$ \\
$\quad$ Lignin & $9.2 \pm 0.30^{\mathrm{a}}$ & $9.49 \pm 0.40^{\mathrm{a}}$ \\
$\quad$ Cellulose & $6.53 \pm 1.10^{\mathrm{a}}$ & $10.31 \pm 0.70^{\mathrm{b}}$ \\
$\quad$ Hemicellulose & $15.51 \pm 2.80^{\mathrm{a}}$ & $24.25 \pm 2.50^{\mathrm{b}}$ \\
$\quad$ Cutin & $7.10 \pm 0.80^{\mathrm{a}}$ & $10.70 \pm 0.50^{\mathrm{b}}$ \\
\hline Caloric value (kJ/100 g) & $3214^{\mathrm{a}}$ & $1080^{\mathrm{b}}$ \\
\hline
\end{tabular}

LEE, lyophilized extract of $E$. edulis fruits; LDEE, defatted lyophilized extract of E. edulis fruits; -, absent component. Data are expressed as mean of five replicates \pm standard deviation. ${ }^{\mathrm{a}, \mathrm{b}}$ Means followed by the same letter in the line do not differ statistically among themselves.

TABLE 2: Polyphenols, anthocyanins, and in vitro antioxidant capacity of lyophilized extracts and oil of E. edulis fruits.

\begin{tabular}{lcc}
\hline Components & LEE & LDEE \\
\hline Polyphenols (mg GAE/g) & $4.10 \pm 0.13^{\mathrm{a}}$ & $4.95 \pm 0.07^{\mathrm{b}}$ \\
Anthocyanins (mg GAE/g) & $2130 \pm 114^{\mathrm{a}}$ & $3121 \pm 139^{\mathrm{b}}$ \\
Antioxidant capacity (mg/L) & $3020 \pm 80.00^{\mathrm{a}}$ & $1428 \pm 66.00^{\mathrm{b}}$ \\
\hline
\end{tabular}

LEE, lyophilized extract of E. edulis fruits; LDEE, defatted lyophilized extract of E. edulis fruits. GAE, gallic acid equivalent. The results were expressed as mean of five replicates \pm standard deviation. ${ }^{\mathrm{a}, \mathrm{b}}$ Means followed by the same letter in the line do not differ statistically among themselves.

TABLE 3: Vitamin E content in lyophilized extracts and oil of E. edulis fruits.

\begin{tabular}{lccc}
\hline Components & LEE & LDEE & EO \\
\hline$\alpha$-tocopherol & $32.17 \pm 0.61^{\mathrm{a}}$ & $2.10 \pm 0.30^{\mathrm{b}}$ & $140.45 \pm 3.56^{\mathrm{c}}$ \\
$\beta$-tocopherol & $1.50 \pm 0.01^{\mathrm{a}}$ & $0.11 \pm 0.01^{\mathrm{b}}$ & $7.10 \pm 0.07^{\mathrm{c}}$ \\
$\gamma$-tocopherol & $1.71 \pm 0.01^{\mathrm{a}}$ & $0.10 \pm 0.01^{\mathrm{b}}$ & $7.37 \pm 0.03^{\mathrm{c}}$ \\
Total vitamin $^{1}$ & $35.38 \pm 0.61^{\mathrm{a}}$ & $2.31 \pm 0.03^{\mathrm{b}}$ & $154.92 \pm 3.67^{\mathrm{c}}$ \\
$\alpha$-tocopherol activity & $33.09 \pm 0.62^{\mathrm{a}}$ & $2.16 \pm 0.03^{\mathrm{b}}$ & $144.74 \pm 2.60^{\mathrm{c}}$ \\
\hline
\end{tabular}

LEE, lyophilized extract of E. edulis fruits; LDEE, defatted lyophilized extract of E. edulis fruits; EO, E. edulis oil. ${ }^{1}$ Obtained by summing the concentrations of all isomers, with a weight of 1 for $\alpha$-tocopherol and 0.3 for $\beta$ - and $\gamma$ tocopherol. The results were expressed as mean of five replicates \pm standard deviation. ${ }^{\mathrm{a}, \mathrm{b}, \mathrm{c}}$ Means followed by the same letter in the line do not differ statistically among themselves.

and LDEE (Table 3). The main fatty acids identified in EO were unsaturated $(76.6 \%)$, with a preponderance of oleic acid (50.29\%) and linoleic acid (24.24\%, Table 4).

The HFD was effective in inducing marked liver steatosis in rats (G1). The control group (G7), which received a conventional diet, presented a normal liver structure with hepatocytes regularly organized in a cordonal pattern. No evidence of liver steatosis was observed in this group (Figure 1). All stereological parameters analyzed were completely impaired
TABLE 4: Fatty acids profile of E. edulis fruits oil.

\begin{tabular}{lcc}
\hline Specification & Content (\%) & Retention time (min) \\
\hline Palmitic acid (16:0) & $21.30 \pm 0.20$ & 24.191 \\
Behenic acid (22:0) & $0.04 \pm 0.04$ & 34.785 \\
Margaric acid (17:0) & $0.02 \pm 0.03$ & 26.240 \\
Arachidic acid (20:0) & $0.06 \pm 0.07$ & 31.342 \\
Stearic acid (18:0) & $1.99 \pm 0.00$ & 27.833 \\
\hline$\sum$ Unsaturated fatty acids & 23.4 & \\
\hline Linoleic acid $\left(18: 2^{\Delta 9,12}\right)$ & $24.24 \pm 0.25$ & 30.572 \\
Palmitoleic acid $\left(16: 1^{\Delta 9}\right)$ & $1.16 \pm 0.07$ & 25.411 \\
Gadoleic acid $\left(20: 1^{\Delta 11}\right)$ & $0.49 \pm 0.45$ & 32.486 \\
Oleic acid (18:1 $\left.1^{\Delta 9}\right)$ & $50.29 \pm 0.52$ & 29.048 \\
Margaroleic acid $\left(17: 1^{\Delta 9}\right)$ & $0.04 \pm 0.02$ & 27.370 \\
\hline$\sum$ Saturated fatty acids & 76.6 & \\
\hline
\end{tabular}

The results were expressed as mean \pm standard deviation of five replicates and expressed in fresh base. Chromatographic conditions are according to the Association of Official Analytical Chemists [18].

in G1 compared to G7 ( $p<0.05$, Table 5). These results indicated that animals in G1 presented intense parenchymal hypotrophy $\left(V_{\mathrm{v}}\right.$ [hep] and $\left.V[\mathrm{HN}]\right)$, tissue conjunctivalization $\left(V_{\mathrm{v}}\right.$ [int $\left.]\right)$, and inflammatory infiltrate $\left(V_{\mathrm{v}}\right.$ [inf]) and proved the accumulation of lipid droplets $\left(V_{\mathrm{v}}[\mathrm{LD}]\right)$ in liver tissue (a pathognomonic feature of steatosis). In general, these parameters were similar in animals receiving EO and attenuated in those treated with 10\% LDEE (G6) compared to G1 $(p<0.05)$. Supplementation with 10\% LEE (G4) was also effective in reducing inflammatory infiltrate in liver tissue compared to G1 $(p<0.05)$.

In general, the animals that received $E$. edulis extracts (LEE [G3 and G4] and LDEE [G5 and G6]), but not EO (G2), exhibited reduced MDA levels in liver tissue compared to G1 $(p<0.05$, Figure 2). CAT and GST activities were lower in groups G4 and G6, and SOD content was lower in all groups receiving LEE and LDEE, both compared to G1 $(p<0.05)$. The lowest results for MDA and antioxidant enzymes were observed in G6.

The results of the serum biochemical analysis are shown in Table 6. Total cholesterol serum levels in G6 and G7 were similar but reduced compared to G1, G2, and G3 $(p<$ 0.05). The levels of CRP, AST, ALT, triacylglycerol, and HDL cholesterol were similar in all groups $(p>0.05)$.

\section{Discussion}

In this study, we investigated the chemical composition of three derivatives obtained from E. edulis fruit and their applicability to protect liver tissue against diet-induced NAFLD in rats. Our results showed that E. edulis pulp is rich in carbohydrates and lipids, which is the main determinant of the high energy value of this pulp. In addition, all E. edulis products (integral extract [LEE], degreased extract [LDEE], and vegetal oil [EO]) presented high levels of antioxidant metabolites. The lipid fraction of E. edulis fruit has a higher polyunsaturated fatty acid content and a lower saturated lipid content, which makes it suitable for human consumption [11]. 

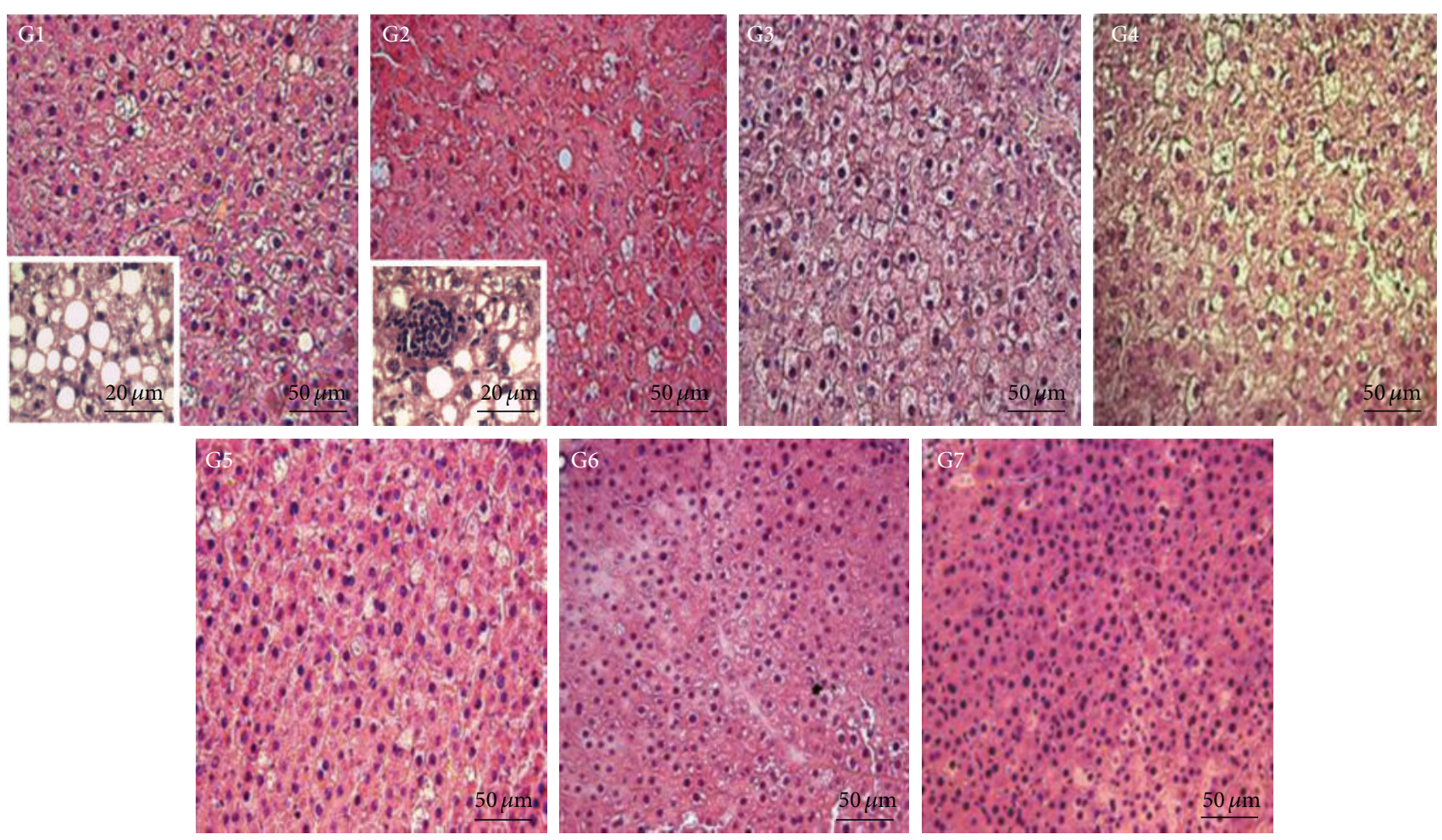

FIGURE 1: Representative photomicrographs of the liver tissue from rats treated with a high-fat diet (HFD) and the lyophilized extracts and oil of E. edulis fruits. LEE, lyophilized extract of E. edulis fruits; LDEE, defatted lyophilized extract of E. edulis fruits; EO, E. edulis oil. G1, HFD; G2, HFD + 4\% EO; G3, HFD + 5\% LEE; G4, HFD + 10\% LEE; G5, HFD + 5\% LDEE; G6, HFD + 10\% LDEE; G7, commercial diet. The image highlighted in G1 indicates macrovesicular steatosis and in G2 inflammatory foci are additionally observed.

TABLE 5: Stereological parameters of the liver tissue from rats treated with a high-fat diet (HFD) and the lyophilized extracts and oil of $E$. edulis fruits.

\begin{tabular}{lcccrrr}
\hline Groups & $V_{\mathrm{v}}$ [hep], \% & $V_{\mathrm{v}}$ [int], \% & $V_{\mathrm{v}}$ [cap], \% & $V_{\mathrm{v}}[\mathrm{Inf}], \%$ & $V_{\mathrm{v}}[\mathrm{LD}], \%$ & $V[\mathrm{HN}], \mu \mathrm{m}^{3}$ \\
\hline G1 & $78.11 \pm 2.07^{\mathrm{a}, \mathrm{b}}$ & $21.89 \pm 2.07^{\mathrm{a}, \mathrm{b}}$ & $9.26 \pm 1.70^{\mathrm{a}}$ & $6.63 \pm 1.27^{\mathrm{a}}$ & $23.39 \pm 3.66^{\mathrm{a}, \mathrm{b}}$ & $428.11 \pm 27.31^{\mathrm{a}}$ \\
G2 & $75.15 \pm 2.31^{\mathrm{a}}$ & $24.85 \pm 2.31^{\mathrm{a}}$ & $9.58 \pm 2.02^{\mathrm{a}}$ & $6.97 \pm 1.83^{\mathrm{a}}$ & $25.18 \pm 3.82^{\mathrm{a}}$ & $412.25 \pm 30.12^{\mathrm{a}}$ \\
G3 & $78.02 \pm 1.93^{\mathrm{a}, \mathrm{b}}$ & $21.98 \pm 1.93^{\mathrm{a}, \mathrm{b}}$ & $10.05 \pm 1.77^{\mathrm{a}}$ & $6.81 \pm 1.66^{\mathrm{a}}$ & $22.05 \pm 3.27^{\mathrm{a}, \mathrm{b}}$ & $436.41 \pm 22.62^{\mathrm{a}}$ \\
G4 & $78.39 \pm 2.11^{\mathrm{a}, \mathrm{b}}$ & $21.61 \pm 2.11^{\mathrm{a}, \mathrm{b}}$ & $10.73 \pm 2.05^{\mathrm{a}}$ & $4.50 \pm 1.35^{\mathrm{b}}$ & $24.12 \pm 3.39^{\mathrm{a}}$ & $505.37 \pm 24.39^{\mathrm{b}}$ \\
G5 & $78.92 \pm 2.55^{\mathrm{a}, \mathrm{b}}$ & $21.08 \pm 2.55^{\mathrm{a}, \mathrm{b}}$ & $9.81 \pm 1.62^{\mathrm{a}}$ & $5.02 \pm 1.42^{\mathrm{a}, \mathrm{b}}$ & $20.26 \pm 3.18^{\mathrm{b}}$ & $459.13 \pm 25.18^{\mathrm{a}}$ \\
G6 & $79.75 \pm 2.47^{\mathrm{b}}$ & $20.25 \pm 2.47^{\mathrm{b}}$ & $9.67 \pm 1.75^{\mathrm{a}}$ & $4.01 \pm 1.19^{\mathrm{b}}$ & $19.07 \pm 2.95^{\mathrm{b}}$ & $512.58 \pm 21.72^{\mathrm{b}}$ \\
G7 & $83.37 \pm 1.89^{\mathrm{c}}$ & $17.63 \pm 1.89^{\mathrm{c}}$ & $10.40 \pm 1.14^{\mathrm{a}}$ & $3.11 \pm 1.03^{\mathrm{c}}$ & $7.38 \pm 2.71^{\mathrm{c}}$ & $573.81 \pm 20.13^{\mathrm{c}}$ \\
\hline
\end{tabular}

LEE, lyophilized extract of E. edulis fruits; LDEE, defatted lyophilized extract of E. edulis fruits; EO, E. edulis oil. $V_{\mathrm{v}}$, volume density; hep, hepatocytes; int, interstitium; cap, capillaries; inflammatory cells; LD, lipid droplets; HN, hepatocytes nuclei. G1, HFD; G2, HFD + 4\% EO; G3, HFD + 5\% LEE; G4, HFD + 10\% LEE; G5, HFD + 5\% LDEE; G6, HFD + 10\% LDEE; G7, commercial diet. ${ }^{\mathrm{a}, \mathrm{b}, \mathrm{c}}$ Different letters in columns denote statistic difference among the groups, $p<0.05$.

Similar results for the fatty acid composition of E. edulis were found by Borges et al. [15] and Neida and Elba [33], who demonstrated the predominance of oleic and linoleic acids in E. edulis and E. oleracea fruits, respectively. Although the Amazon rainforest açaí (E. oleracea fruit) has excelled in the international market ( $\$ 121.7 \mathrm{~m}$ a year in the USA) [34], the Atlantic Forest açaí (E. edulis fruit) is still a food resource little explored. However, from a nutritional point of view, the chemical composition of E. edulis $[13,15,17]$ and E. oleracea is similar [33, 35-37], corroborating the use of E. edulis fruit as a valuable food resource.
Both derivatives EO and LEE were rich in vitamin E. Due to the content of polyphenols and anthocyanins, LEE and LDEE presented high antioxidant activity in vitro. The degreasing process of LEE proved to be effective in increasing polyphenols and anthocyanins, resulting in an enhanced antioxidant capacity of LDEE. This finding indicated that, as expected, the antioxidant capacity of E. edulis fruit is related to its polyphenolic compounds. In fact, in a recent study we also proved the high content of anthocyanins $(301.4 \mathrm{mg} / 100 \mathrm{~g}$ dry extract, especially cyanidin-3-glucoside and cyanidin3-rutinoside) in an E. edulis extract similar to LEE [17]. 

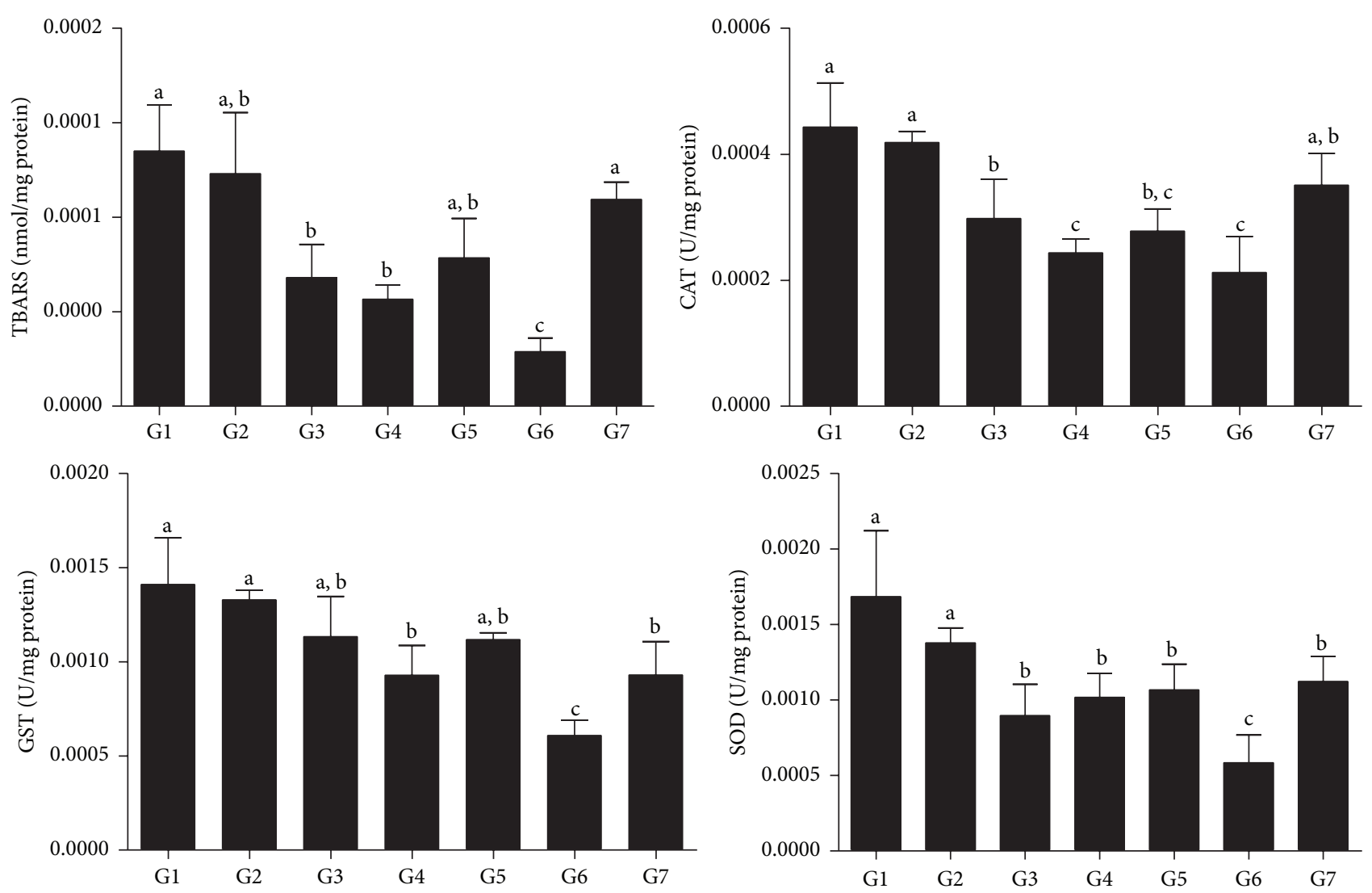

FIGURE 2: Markers of oxidative status in the liver tissue from rats treated with a high-fat diet (HFD) and the lyophilized extracts and oil of $E$. edulis fruits. MDA, malondialdehyde; CAT, catalase; GST, glutathione-s-transferase; SOD, superoxide dismutase. LEE, lyophilized extract of E. edulis fruits; LDEE, defatted lyophilized extract of E. edulis fruits; EO, E. edulis oil. G1, HFD; G2, HFD + 4\% EO; G3, HFD + 5\% LEE; G4, HFD + 10\% LEE; G5, HFD + 5\% LDEE; G6, HFD + 10\% LDEE; G7, commercial diet. ${ }^{\text {a,b,c }}$ Different letters in columns denote statistic difference between the groups, $p<0.05$.

TABLE 6: Serum biochemical parameters (U/L) of rats treated with a hypercholesterolemic diet and E. edulis.

\begin{tabular}{|c|c|c|c|c|c|c|c|c|}
\hline & US-PCR & Glucose & TC & TG & HDL & AST & ALT & ALP \\
\hline G1 & $0.30 \pm 0.12^{\mathrm{a}}$ & $194.00 \pm 54.70^{\mathrm{a}, \mathrm{b}}$ & $57.33 \pm 5.75^{\mathrm{a}}$ & $89.66 \pm 38.83^{\mathrm{a}}$ & $33.16 \pm 5.49^{\mathrm{a}}$ & $172.16 \pm 98.65^{\mathrm{a}}$ & $55.00 \pm 18.91^{\mathrm{a}}$ & $121.66 \pm 30.6^{\mathrm{a}}$ \\
\hline G2 & $0.37 \pm 0.17^{\mathrm{a}}$ & $159.66 \pm 12.29^{\mathrm{a}, \mathrm{b}}$ & $50.83 \pm 5.70^{\mathrm{a}}$ & $98.33 \pm 19.45^{\mathrm{a}}$ & $36.83 \pm 4.07^{\mathrm{a}}$ & $183.16 \pm 89.49^{\mathrm{a}}$ & $73.83 \pm 29.90^{\mathrm{a}}$ & $179.00 \pm 73.26^{\mathrm{a}}$ \\
\hline G3 & $0.66 \pm 0.47^{\mathrm{a}}$ & $158.00 \pm 13.57^{\mathrm{a}, \mathrm{b}}$ & $53.50 \pm 6.05^{\mathrm{a}}$ & $91.83 \pm 11.30^{\mathrm{a}}$ & $35.16 \pm 1.72^{\mathrm{a}}$ & $123.00 \pm 32.92^{\mathrm{a}}$ & $59.50 \pm 21.49^{\mathrm{a}}$ & $170.16 \pm 46.81^{\mathrm{a}}$ \\
\hline G4 & $0.42 \pm 0.15^{\mathrm{a}}$ & $190.16 \pm 20.12^{\mathrm{a}}$ & $62.50 \pm 11.23^{\mathrm{a}, \mathrm{c}}$ & $124.83 \pm 44.52^{\mathrm{a}}$ & $36.33 \pm 5.20^{\mathrm{a}}$ & $101.00 \pm 23.09^{\mathrm{a}}$ & $44.50 \pm 10.82^{\mathrm{a}}$ & $166.83 \pm 48.14^{\mathrm{a}}$ \\
\hline G5 & $0.57 \pm 0.22^{\mathrm{a}}$ & $196.83 \pm 27.12^{\mathrm{a}}$ & $57.66 \pm 3.44^{\mathrm{a}, \mathrm{b}}$ & $122.33 \pm 42.54^{\mathrm{a}}$ & $31.83 \pm 3.25^{\mathrm{a}}$ & $113.00 \pm 19.40^{\mathrm{a}}$ & $44.50 \pm 8.52^{\mathrm{a}}$ & $143.33 \pm 30.28^{\mathrm{a}}$ \\
\hline G6 & $0.21 \pm 0.11^{\mathrm{a}}$ & $200.66 \pm 22.90^{\mathrm{a}}$ & $66.66 \pm 8.28^{\mathrm{b}, \mathrm{c}}$ & $114.83 \pm 65.48^{\mathrm{a}}$ & $34.66 \pm 3.55^{\mathrm{a}}$ & $94.00 \pm 25.04^{\mathrm{a}}$ & $52.00 \pm 39.37^{\mathrm{a}}$ & $130.33 \pm 46.24^{\mathrm{a}}$ \\
\hline G7 & $0.36 \pm 0.18^{\mathrm{a}}$ & $139.66 \pm 18.47^{\mathrm{b}}$ & $69.50 \pm 8.82^{b, c}$ & $75.66 \pm 11.41^{\mathrm{a}}$ & $37.16 \pm 8.97^{\mathrm{a}}$ & $137.33 \pm 38.95^{\mathrm{a}}$ & $51.33 \pm 14.47^{\mathrm{a}}$ & $60.50 \pm 25.86^{\mathrm{b}}$ \\
\hline
\end{tabular}

US-PCR, ultrasensitive C-reactive protein; TC, total cholesterol; TG, triglycerides; HDL, high density lipoproteins; AST, alanine aminotransferase; ALT, aspartate aminotransferase, ALP, alkaline phosphatase. G1, CD; G2, CD + 4\% OE; G3, CD + 5\% LEE; G4, CD + 10\% LEE; G5, CD + 5\% LEDE; G6, CD + 10\% LEDE; G7, commercial diet. ${ }^{\text {a,b,c }}$ Different letters in columns denote statistic difference between the groups, $p<0.05$.

There is evidence that anthocyanins such as cyanidin-3-Oglucoside and cyanidin-3-O-rutinoside have high antioxidant activity against peroxyl, hydroxyl, and peroxynitrite radicals, an effect potentially associated with the antioxidant capacity of E. oleracea pulp in vivo [37].

When tested in rats, dietary intake of LEE and LDEE, but not EO, was effective in mitigating the development or severity of NAFLD in rats fed an HFD. The extracts, especially LDEE at the highest dose (10\%), had a positive impact in reducing hepatocyte hypotrophy, inflammatory infiltrate, microvesicular steatosis, and lipid peroxidation in liver tissue (i.e., MDA). Lipid accumulation, inflammation, and oxidative stress are three pivotal interdependent events in NAFLD pathogenesis $[1,38]$. There is evidence that this triad feeds itself in a cycle that worsens morphological and functional liver damage $[1,5,38,39]$. As a result of inflammatory processes, the activation of leucocytes increases the production of oxidizing agents such as nitric oxide (NO), superoxide 
$\left(\mathrm{O}_{2}^{-}\right)$, and hydroxyl $\left(\mathrm{OH}^{-}\right)$radicals, which are known for amplifying oxidative damage and hepatic dysfunction, including steatosis $[24,25,28]$. Thus, antioxidants and antiinflammatory drugs have been indicated as rational strategies to prevent and treat NAFLD $[2,5]$. Previous studies showed that dietary intake of plant extracts rich in phenols and anthocyanins is capable of downregulating the oxidation of lipids and cell proteins, reducing the inflammatory process and the severity of liver steatosis $[13,14,17]$. The antioxidant activity of many fruits comes from the combined synergic actions of compounds such as phenols, flavonoids, carotenoids, and vitamins $\mathrm{C}$ and $\mathrm{E}[33,40]$. However, in fruits like açaí, polyphenols and anthocyanins are the main contributors to the antioxidant capacity $[14,17,35]$.

As expected, the diet-induced NAFLD triggered liver oxidative stress, requiring a reactive upregulation of antioxidant enzymes. Considering a mechanistic approach, we investigated whether these extracts acted by a direct or indirect way to mitigate lipid peroxidation. In general, while the animals receiving HFD alone or combined with EO presented high MDA levels and increased activities of CAT, SOD, and GST, the animals treated with LEE and LDEE showed the opposite. Thus, these findings indicated that both extracts act in a direct way (independent of the endogenous antioxidant enzymatic system) to neutralize reactive metabolites and modulate the oxidative status. It is possible that, by effectively neutralizing free radicals, LEE and LDEE reduce the consumption of antioxidant enzymes in antioxidant defense processes. This effect is remarkable since the exhaustion of antioxidant enzymes by mass production of free radicals is a pivotal mechanism of tissue damage [24-26]. However, several plant extracts rich in phenol compounds also act by upregulating the expression and activity of antioxidant enzymes, modulating endogenous antioxidant defenses $[24,25,36]$. Although there is evidence that the major anthocyanin of E. edulis and E. oleracea pulp (cyanidin-3-glucoside) is effective in suppressing the activity of antioxidant enzymes in rats [37], this is a poorly understood issue that requires further investigation.

While LEE and LDEE showed beneficial results, EO dietary intake presented no effect on NAFLD. Thus, animals treated with EO and those receiving HFD alone had high and similar liver damage. Considering that the high activity of CAT, SOD, and GST was similarly observed in these animals, it is possible that the content of vitamin $\mathrm{E}$ in $\mathrm{EO}$ is not enough to restrict the oxidative stress associated with diet-induced NAFLD. Although previous studies have shown a high antioxidant potential of açaí oil $[15,16,35]$, this effect seems not to be reproducible in vivo. Considering the complexity of the disease model applied here, the absence of antioxidant activity cannot be exclusively attributed to the chemical composition of EO. As HFD is a robust model of obesity and NAFLD in rats $[6,41]$, it is reasonable to assume that additional lipid intake provided by EO supplementation could not be beneficial to treating NAFLD. However, as with LEE and LDEE, EO intake presented no evidence of liver toxicity, since CRP, ALT, and AST serum levels [42] were similar in all groups. Besides no apparent toxicity, larger doses and periods of administration should be investigated before determining the safety level and applicability of these E. edulis derivatives as food supplements.

Taken together, our results indicated that E. edulis pulp is a useful source of natural extracts and oil with high nutritional or biological properties. As determined by chemical analysis, unsaturated lipids are the main components responsible for the high energy value of LEE. By removing LEE lipid content, its degreased derivative (LDEE) presented increased antioxidant capacity in vitro, which was determined by higher levels of phenols and anthocyanins. When tested in vivo, the antioxidant potentials of LEE and LDEE were independent of endogenous antioxidant enzymes. Moreover, dietary intake of LEE and especially LDEE, but not EO, proved to be beneficial in attenuating diet-induced NAFLD in rats, reducing hepatocyte hypotrophy, inflammatory infiltrate, steatosis, and lipid peroxidation in liver tissue. As no morphological or functional parameter associated with hepatic steatosis was aggravated, the dietary intake of E. edulis derivatives seems to be safe. However, further clinical studies are still required in order to determine whether E. edulis pulp and its derivatives can be used as dietary supplements in the management of NAFLD induced by HFD.

$\begin{array}{ll}\text { Abbreviations } \\ \text { LEE: } & \text { Lyophilized pulp } \\ \text { LDEE: } & \text { Defatted lyophilized } \\ \text { EO: } & \text { Pulp oil } \\ \text { HFD: } & \text { High-fat diet } \\ \text { NAFLD: } & \text { Nonalcoholic fatty liver disease } \\ \text { ALT: } & \text { Alanine aminotransferase } \\ \text { AST: } & \text { Aspartate aminotransferase } \\ \text { AOAC: } & \text { Association of Official Analytical Chemists } \\ \text { DPPH: } & \text { 2,2-Diphenyl-1-picrylhydrazyl } \\ \text { TAC: } & \text { Total anthocyanin content } \\ V_{\mathrm{v}}: & \text { Volume density } \\ \text { TBARS: } & \text { Thiobarbituric acid reactive substances } \\ \text { CAT: } & \text { Catalase } \\ \text { GST: } & \text { Glutathione-s-transferase } \\ \text { SOD: } & \text { Superoxide dismutase } \\ \mathrm{H}_{2} \mathrm{O}_{2}: & \text { Hydrogen peroxide. }\end{array}$

\section{Competing Interests}

The authors declare no competing interests.

\section{Acknowledgments}

This work was supported by Fundação de Amparo à Pesquisa do Estado de Minas Gerais (FAPEMIG), Brazil.

\section{References}

[1] D. G. Tiniakos, M. B. Vos, and E. M. Brunt, "Nonalcoholic fatty liver disease: pathology and pathogenesis," Annual Review of Pathology: Mechanisms of Disease, vol. 5, pp. 145-171, 2010.

[2] R. L. Corrado, D. M. Torres, and S. A. Harrison, "Review of treatment options for nonalcoholic fatty liver disease," Medical Clinics of North America, vol. 98, no. 1, pp. 55-72, 2014. 
[3] Z. M. Younossi, M. Stepanova, M. Afendy et al., "Changes in the prevalence of the most common causes of chronic liver diseases in the united states from 1988 to 2008," Clinical Gastroenterology and Hepatology, vol. 9, no. 6, pp. 524-530, 2011.

[4] S. A. Polyzos, J. Kountouras, C. Zavos, and G. Deretzi, "Nonalcoholic fatty liver disease: multimodal treatment options for a pathogenetically multiple-hit disease," Journal of Clinical Gastroenterology, vol. 46, no. 4, pp. 272-284, 2012.

[5] B. Lam and Z. M. Younossi, "Treatment options for nonalcoholic fatty liver disease," Therapeutic Advances in Gastroenterology, vol. 3, no. 2, pp. 121-137, 2010.

[6] B. P. Sampey, A. M. Vanhoose, H. M. Winfield et al., "Cafeteria diet is a robust model of human metabolic syndrome with liver and adipose inflammation: comparison to high-fat diet," Obesity, vol. 19, no. 6, pp. 1109-1117, 2011.

[7] Z. Bahadoran, P. Mirmiran, and F. Azizi, "Dietary polyphenols as potential nutraceuticals in management of diabetes: a review," Journal of Diabetes and Metabolic Disorders, vol. 12, no. 1, article 43, 2013.

[8] Y. Qin, M. Xia, J. Ma et al., "Anthocyanin supplementation improves serum LDL- and HDL-cholesterol concentrations associated with the inhibition of cholesteryl ester transfer protein in dyslipidemic subjects," American Journal of Clinical Nutrition, vol. 90, no. 3, pp. 485-492, 2009.

[9] K. B. Pandey and S. I. Rizvi, "Plant polyphenols as dietary antioxidants in human health and disease," Oxidative Medicine and Cellular Longevity, vol. 2, no. 5, pp. 270-278, 2009.

[10] P. C. H. Hollman, A. Cassidy, B. Comte et al., "The biological relevance of direct antioxidant effects of polyphenols for cardiovascular health in humans is not established," Journal of Nutrition, vol. 141, no. 5, pp. 989-1009, 2011.

[11] C. R. Sirtori, C. Galli, J. W. Anderson, E. Sirtori, and A. Arnoldi, "Functional foods for dyslipidaemia and cardiovascular risk prevention," Nutrition Research Reviews, vol. 22, no. 2, pp. 244261, 2009.

[12] Y. P. Hwang, J. H. Choi, E. H. Han et al., "Purple sweet potato anthocyanins attenuate hepatic lipid accumulation through activating adenosine monophosphate-activated protein kinase in human HepG2 cells and obese mice," Nutrition Research, vol. 31, no. 12, pp. 896-906, 2011.

[13] C. A. De Castro, A. J. Natali, L. M. Cardoso et al., "Aerobic exercise and not a diet supplemented with jussara açaí (Euterpe edulis Martius) alters hepatic oxidative and inflammatory biomarkers in ApoE-deficient mice," British Journal of Nutrition, vol. 112, no. 3, pp. 285-294, 2014.

[14] I. Rodriguez-Ramiro, D. Vauzour, and A. M. Minihane, "Polyphenols and non-alcoholic fatty liver disease: impact and mechanisms," Proceedings of the Nutrition Society, vol. 75, no. 01, pp. 47-60, 2016.

[15] G. D. C. Borges, F. G. K. Vieira, C. Copetti et al., "Chemical characterization, bioactive compounds, and antioxidant capacity of jussara (Euterpe edulis) fruit from the Atlantic Forest in southern Brazil," Food Research International, vol. 44, no. 7, pp. 2128-2133, 2011.

[16] C. P. Lima, M. M. Cunico, C. M. S. Miyazaki et al., "Polyphenolic content and antioxidant capacity of fruits of Juçara (Euterpe edulis Martius) palm tree," Revista Brasileira de Plantas Medicinais, vol. 14, no. 2, pp. 321-326, 2012.

[17] L. M. Cardoso, R. D. Novaes, C. A. de Castro et al., "Chemical composition, characterization of anthocyanins and antioxidant potential of Euterpe edulis fruits: applicability on genetic dyslipidemia and hepatic steatosis in mice," Nutrición Hospitalaria, vol. 32, no. 2, pp. 702-709, 2015.

[18] AOAC International, Official Methods of Analysis of AOAC International, AOAC International, Washington, DC, USA, 2007.

[19] P. Van Soest, "Use of detergents in analysis of fibrous feeds. 3. Study of effects of heating and drying on yield of fiber and lignin in forages," Journal of Association of Official Analytical Chemists, vol. 48, pp. 785-790, 1965.

[20] V. L. Singleton, R. Orthofer, and R. M. Lamuela-Raventos, "Analysis of total phenols and other oxidation substrates and antioxidants by means of Folin-Ciocalteu reagent," Methods in Enzymology, vol. 299, pp. 152-178, 1999.

[21] G. W. Cheng and P. J. Breen, "Activity of Phenylalanine Ammonia-Lyase (Pal) and concentrations of anthocyanins and phenolics in developing strawberry fruit," Journal of the American Society for Horticultural Science, vol. 116, no. 5, pp. 865-869, 1991.

[22] W. Brand-Williams, M. E. Cuvelier, and C. Berset, "Use of a free radical method to evaluate antioxidant activity," Food Science and Technology, vol. 28, no. 1, pp. 25-30, 1995.

[23] L. D. M. Cardoso, H. S. D. Martino, A. V. B. Moreira, S. M. R. Ribeiro, and H. M. Pinheiro-Sant'Ana, "Cagaita (Eugenia dysenterica DC.) of the Cerrado of Minas Gerais, Brazil: physical and chemical characterization, carotenoids and vitamins," Food Research International, vol. 44, no. 7, pp. 2151-2154, 2011.

[24] R. V. Gonçalves, R. D. Novaes, J. P. V. Leite et al., "Hepatoprotective effect of Bathysa cuspidata in a murine model of severe toxic liver injury," International Journal of Experimental Pathology, vol. 93, no. 5, pp. 370-376, 2012.

[25] R. D. Novaes, R. V. Gonçalves, D. C. S. Marques et al., "Effect of bark extract of Bathysa cuspidata on hepatic oxidative damage and blood glucose kinetics in rats exposed to paraquat," Toxicologic Pathology, vol. 40, no. 1, pp. 62-70, 2012.

[26] M. C. Cupertino, K. L. C. Costa, D. C. M. Santos et al., "Longlasting morphofunctional remodelling of liver parenchyma and stroma after a single exposure to low and moderate doses of cadmium in rats," International Journal of Experimental Pathology, vol. 94, no. 5, pp. 343-351, 2013.

[27] M. A. Sala, M. C. Komesu, R. A. Lopes, and G. Maia Campos, "Karyometric study of basal cell carcinoma," Brazilian Dental Journal, vol. 5, no. 1, pp. 11-14, 1994.

[28] R. V. Gonçalves, S. L. P. Da Matta, R. D. Novaes, J. P. V. Leite, M. D. C. G. Peluzio, and E. F. Vilela, "Bark extract of Bathysa cuspidata in the treatment of liver injury induced by carbon tetrachloride in rats," Brazilian Archives of Biology and Technology, vol. 57, no. 4, pp. 504-513, 2014.

[29] J. A. Buege and S. D. Aust, "Microsomal lipid peroxidation," Methods in Enzymology, vol. 52, pp. 302-310, 1978.

[30] H. Aebi, "Catalase in vitro," Methods in Enzymology, vol. 105, pp. 121-126, 1984.

[31] J. H. Keen, W. H. Habig, and W. B. Jakoby, "Mechanism for the several activities of the glutathione S-transferases," The Journal of Biological Chemistry, vol. 251, no. 20, pp. 6183-6188, 1976.

[32] S. Sarban, A. Kocyigit, M. Yazar, and U. E. Isikan, "Plasma total antioxidant capacity, lipid peroxidation, and erythrocyte antioxidant enzyme activities in patients with rheumatoid arthritis and osteoarthritis," Clinical Biochemistry, vol. 38, no. 11, pp. 981-986, 2005. 
[33] S. Neida and S. Elba, "Characterization of the acai or manaca (Euterpe oleracea Mart.): a fruit of the Amazon," Archivos Latinoamericanos de Nutricion, vol. 57, no. 1, pp. 94-98, 2007.

[34] Governo do Para, Secretaria de Estado de Indústria CeM. Pará, terra do açaí: oportunidade de investimentos, 2011, http://www.agricultura.gov.br/arq_editor/file/camaras_setoriais/ Fruticultura/34RO/App_Banco_Mundial_Fruticultura.pdf.

[35] M. D. S. M. Rufino, J. Pérez-Jiménez, S. Arranz et al., "Açaí (Euterpe oleraceae) 'BRS Pará': a tropical fruit source of antioxidant dietary fiber and high antioxidant capacity oil," Food Research International, vol. 44, no. 7, pp. 2100-2106, 2011.

[36] M. O. de Souza, M. Silva, M. E. Silva, R. P. Oliveira, and M. L. Pedrosa, "Diet supplementation with acai (Euterpe oleracea Mart.) pulp improves biomarkers of oxidative stress and the serum lipid profile in rats," Nutrition, vol. 26, pp. 804-810, 2006.

[37] T. Tsuda, F. Horio, J. Kitoh, and T. Osawa, "Protective effects of dietary cyanidin 3-O- $\beta$-D-glucoside on liver ischemiareperfusion injury in rats," Archives of Biochemistry and Biophysics, vol. 368, no. 2, pp. 361-366, 1999.

[38] E. Buzzetti, M. Pinzani, and E. A. Tsochatzis, "The multiplehit pathogenesis of non-alcoholic fatty liver disease (NAFLD)," Metabolism: Clinical and Experimental, 2016.

[39] J. Xiao and G. L. Tipoe, "Inflammasomes in non-alcoholic fatty liver disease," Frontiers in Bioscience, vol. 21, no. 4, pp. 683-695, 2016.

[40] E. R. Monsen, "Dietary reference intakes for the antioxidant nutrients: vitamin C, vitamin E, selenium, and carotenoids," Journal of the American Dietetic Association, vol. 100, no. 6, pp. 637-640, 2000.

[41] I. C. Macedo, L. F. Medeiros, C. Oliveira et al., "Cafeteria dietinduced obesity plus chronic stress alter serum leptin levels," Peptides, vol. 38, no. 1, pp. 189-196, 2012.

[42] T. H. Lee, W. R. Kim, and J. J. Poterucha, "Evaluation of elevated liver enzymes," Clinics in Liver Disease, vol. 16, no. 2, pp. 183-198, 2012. 


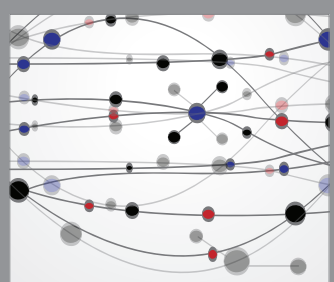

The Scientific World Journal
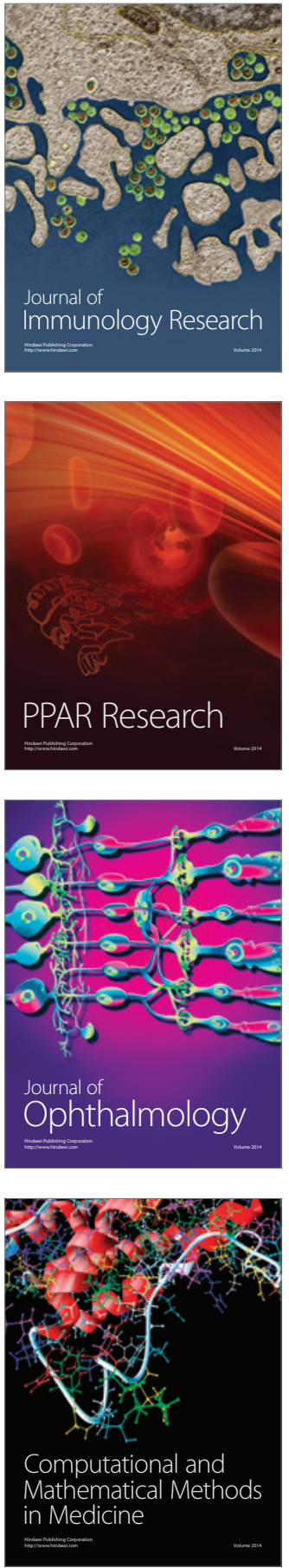

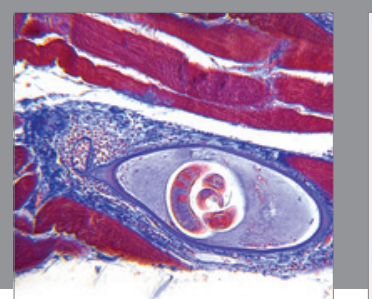

Gastroenterology Research and Practice

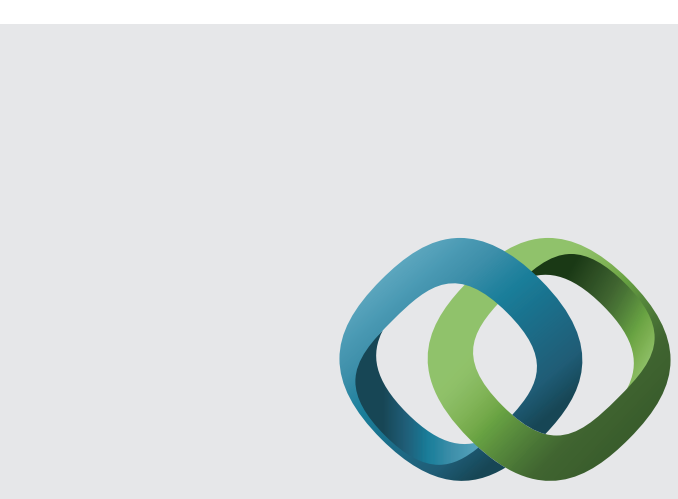

\section{Hindawi}

Submit your manuscripts at

http://www.hindawi.com
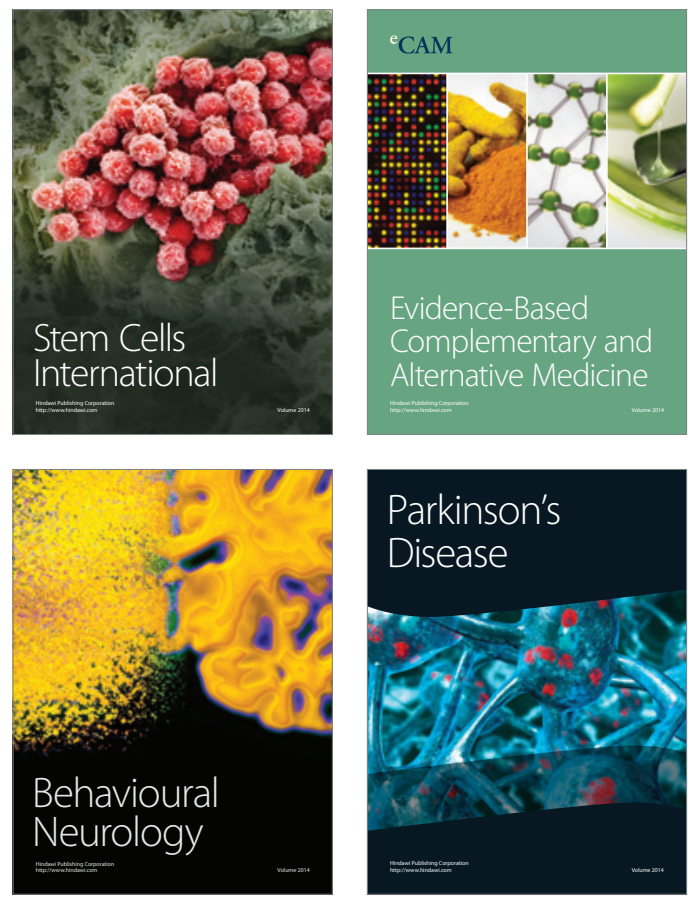
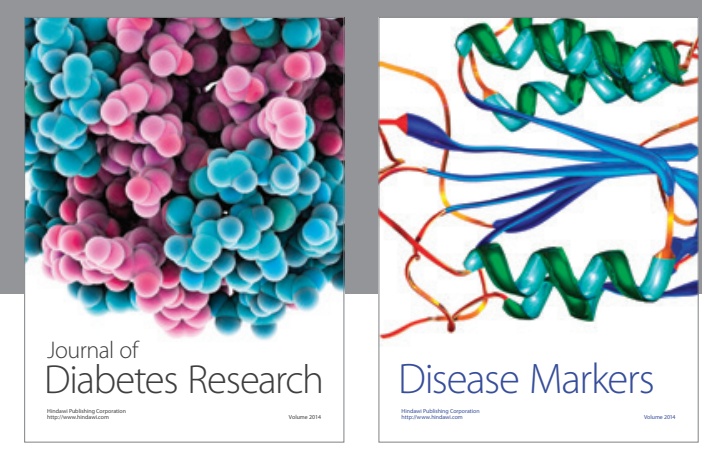

Disease Markers
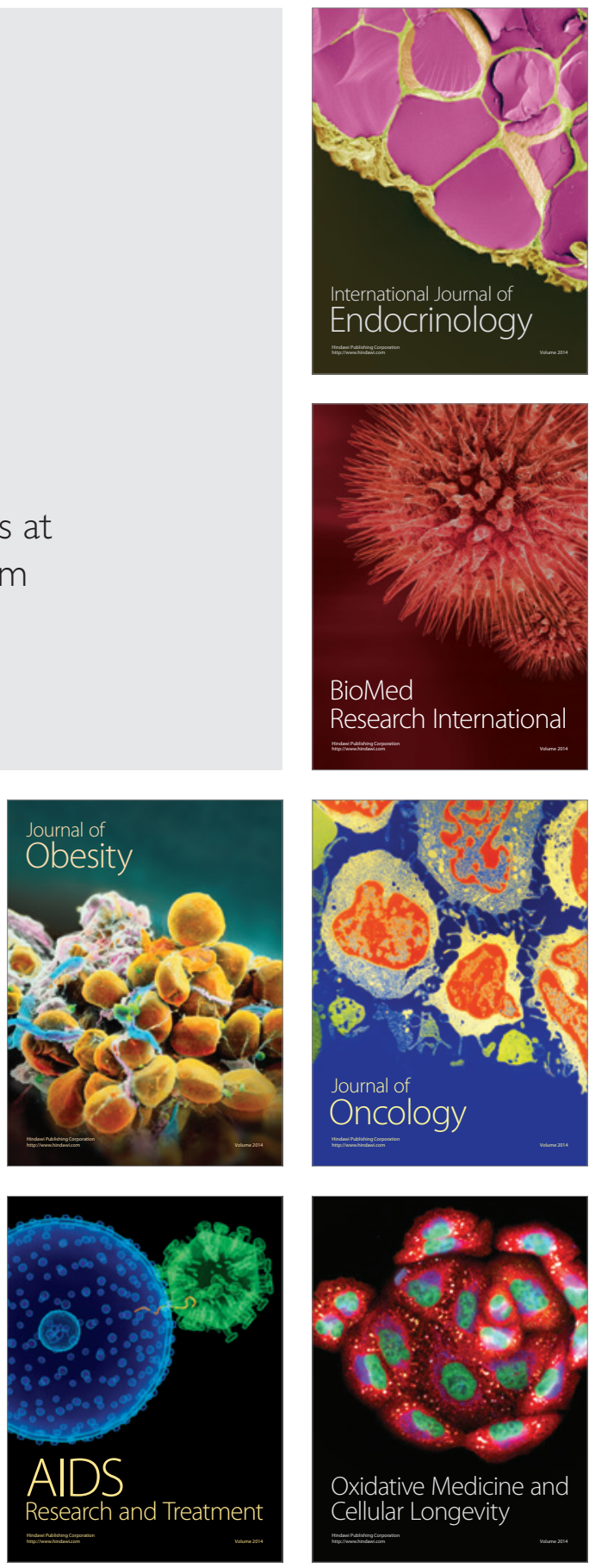